\title{
The Development And Present Situation Of Sports Teaching Mode In China
}

\author{
Liping Hua ${ }^{1}$ \\ ${ }^{1}$ Taishan Medical University, Tai'an, Shandong Province, China
}

Keywords:Sports, Teaching mode, the Status quo, Development trend

\begin{abstract}
China's previous school sports education emphasizes physical training, only ignored the guidance to reasonable maintenance of the body and health. The implementation of quality education, facing all students, create sports health garden, make everyone health. We through the part of the school of investigation and study, the current Chinese school sports education pattern structure, and puts forward some Suggestions, hope to promote Chinese school sports education.
\end{abstract}

\section{Introduction}

At present, with the deepening of the global education reform, education is the major changes in our country. Innovation of the traditional education faces, study and explore the future of education is one of the critical problem in front of people. Marks the world leading position of the United States and other developed countries, have education put forward new requirements for the 21st century [1]. "School education from exam-oriented education to improve national quality the track, facing all students, fully improve the students' ideological and moral, culture, science, labor skills, and physical and mental health, promote the development of the students of lively, their respective characteristics. "Throughout the world education reform, despite different national conditions, education reform must also vary, but is a common characteristic [1]. The common feature is the emphasis on the all-round development of people, especially in improving people's physical and mental quality. It seems that sports education occupies an important position in the school education, the role to the education reform is great.

With the rapid development of China's economy, China's economy has become an integral part of the world economy, construction industry as a pillar industry in China, in the economic construction of stimulating domestic demand, in a rare period of development. As China's market economic system gradually improve, in order to meet the demand of the market economy, to adapt to their corporate culture and brand benefit, must study of construction project management mode, and efforts to improve and innovate [1]. Although China state construction engineering construction enterprise has accumulated rich experience in project management have made great progress, but in the actual process of construction project management, many problems still exist, affect the survival and development of Chinese construction enterprise. For China state construction engineering safety science construction. This paper mainly studies the Chinese construction engineering construction enterprise project management problems, to explore construction engineering management strategy, for the China state construction engineering construction enterprise to provide reference for the further development in the routine management.

\section{China's sports education work status}

Sports is melting gymnastics, music, dance, fitness in one, by unarmed, apparatuses and special light Machinery operating practice, to achieve fitness, fitness, healthy heart, for the purpose of a new entertainment, watch sports. It is easy to learn, small joint action, symmetry action is much, time is long, and the load size can adjust at will, to the all-round development of targeted muscle body itself. At the same time, the sports enthusiasm is bold and unrestrained, rhythm and lively, the action stretches the powerful, in a beautiful, strong music accompaniment, vigorous upward, give a person a kind of spirits, drivers, dance to their heart's content the activists and the viewer feel health and beauty of perfection. 
Sports teaching goals are not clear. In the current "people-oriented", "health first" concept of education, under the guidance of sports teaching goal basically includes: emotional goals, attitude, exchanges and cooperation, experience; Physical fitness goals - development; Based on the goal of forming motor skills; Cognitive goals - concept, principle and knowledge [2]. The teaching goal is the direction in the process of teachers in the teaching practice and the expected orientation, teaching goal realization lies in the teachers' understanding of the teaching goal and execution in the teaching process.

Old sports teaching content. Sports teaching content is the carrier of sports education, it is according to the goal of physical education curriculum, the inherent law of sports teaching and social needs [2]. The choice of sports teaching content should have: the principle of combining practicality with knowledge; the principle of combining the body character and culture; the principle of combining nationality and openness; the principle of combining inheritance and development; Unity combined with flexible.

A single sports teaching mode. Sports teaching pattern is under the guidance of certain physical education teaching thought, according to certain principle design with appropriate structure and function of physical education teaching model or strategy, it is the embodiment of sports teaching system and teaching process and practice, and sports teaching forms and teaching methods of comprehensive carrier [2]. At present, the ordinary university sports teaching model is mainly composed of teaching as the core, with extracurricular activity training as the core, with three sports fitness entertainment as the core process organic integration. The three process in the nature of the course is based mainly on physical education, special physical education, physical education club of three different types of physical education.

The sports idea behind. Sports discipline teaching characteristic is: there is moral education, intellectual education, aesthetic education, physical exercise and strengthen physical education function, other disciplines can only have three aspects of function, after do not have a function [2]. Sports has the characteristics of multi-functional, has certain social value, many people, including a significant number of leaders, think sports is the bouncing up and down, playing games, and not from the height and depth of improving the quality of the whole nation to realize. Concept of lag, greatly hindered the development of rural school sports.

The school sports management system is not perfect. The school sports work management system did not form, sports work not fully embodies in the whole education work planning. Organization become a mere formality, for physical education teachers, extra-curricular sports activities, space equipment construction, the requirements of the sports teaching is still in the fuzzy and "sheep" management style, lack of macro goals and micromanagement consciousness.

Poor operating conditions. School due to funds nervous even run in debt, and no ability to improve sports facilities, sports equipment [3]. This cannot be guaranteed to not only the normal teaching activities. The fear is there are many potential safety hazard in the sports teaching, in order to avoid accident occurs in the school students, would rather give up school physical education.

Deficiencythe quality of teaching and evaluation standard. The good and bad of sports teaching quality, the level of high and low, few people ask. Some school leaders and teachers and parents think students failed the sports performance, not up to standard, and not good and does not affect the bound, also do not take the sports education [3]. Add try sports among junior high school increased during this period, caused the people some of the attention, but after one or two years later, the school began in the examination, one thousand party hundreds more or less help literacy class result good students to cheat, making false sports scores.

\section{The development trend of China's sports teaching mode}

In school education, physical education process, the longest until graduate from kindergarten to university is carrying on the physical education, the development of school sports education is with the development of social history and the inheritance of traditional culture. So at present, the development of the Chinese school sports education must also with China's national conditions, adapted to the need of the society. School physical education should be to promote the all-round 
development of people, make everyone enjoy the sports and health education, the realization of the aim of serving the national modernization construction [3]. It refer to a large number of domestic and foreign literature about school sports education, and organize the relevant experts and scholars of school physical education in this region of investigation, on the part of the school for more than a year of teaching practice, concentration and optimization to determine the structure of the development trend of school physical education idea in school education, physical education process, the longest until graduate students from kindergarten to university on physical education, the development of school sports education is with the development of social history and the inheritance of traditional culture. So at present, the development of the Chinese school sports education must also with China's national conditions, adapted to the need of the society. School physical education should be to promote the all-round development of people, make everyone enjoy the sports and health education, the realization of the aim of serving the national modernization construction. I refer to a large number of domestic and foreign literature about school sports education, and organize the relevant experts and scholars of school physical education in this region of investigation, on the part of the school for more than a year of teaching practice, concentrated and optimization to determine the structure of the development trend of school physical education.

Guided by the quality of sports education. Quality physical education is a branch of quality education thoughts. How all the students take part in physical exercise consciousness, how all the students' physique, and lifelong exercise methods how to education, health, sports and so on are all its connotation [4]. Therefore, school sports education must be geared to the needs of all students, fully improve the students' physical and mental health, undertake to the student physical culture education, make students have a healthy body, healthy psychology and sound personality, namely the healthy development of physical and mental are. What is the health of body and mind quality, how to through to the school sports education? Health of body and mind quality, namely, physical health and mental health qualities. The physical and mental health diathesis is the material base for developing other qualities. MAO Zedong early in the research of sports said: "sports together, with the moral education and intellectual education and moral education are sent in the body, nobody is no virtue also". "Body, drive the car and the house of the combine moral" of knowledge. Health of body and mind quality support for developing intelligence, stability and individual normal work and study, are of special significance, the current "college entrance examination in the first ten phenomenon" is precisely illustrates this point [4]. Health of body and mind quality include physical health quality, and physical health quality, and physical quality of the body organs physiological function (that is, strength endurance speed sensitive coordination, etc. ) and the human body for a variety of stimulating reflection, ability to adapt and tolerance, etc. Through the practice has proved that the quality of the physical and mental health education is influence and improve the students' psychological health level of activity process. Specifically, the physical and mental health to achieve the goal of quality education is: on the basis of the innate physical and mental health quality, make the educate has a strong and handsome of posture, good health, full of vigor and vitality of fitness and form a stable state of mind and good physical exercise habits. Make the educates various parts of the body, each system for the development of harmonious and unified, enhance adaptability and athletic ability of the external environment, to adapt to the tense learning working rhythm and complex challenges of the situation.

Based on the sports health education. Health education and school health education as early as 1800 American educationist Mr Column 'first proposed the concept of health education and school health education. The world health organization: nearly billion worldwide most of the children are in school, so school health education will be in order to reach the goal of global health provides a great opportunity [5]. Because today's children will become tomorrow's parents, citizens and leaders, their health will affect the future of the world. World, scientific and cultural organization (UNESCO) published the comprehensive school health education: action guide pointed out that health education for every child is the basic power of youth, to improve their health values and practice ability, promote the health level of people all over the world. School health education has experienced from the emphasis on knowledge transmission to emphasize behavior training and emphasize the 
development of the environment to support. Physical education in the new period through the sports teaching to the student physical health care education, strengthen students' physique, promote health of body and mind development, cultivating virtue, wisdom, body, beauty comprehensive development of the builders of socialism. So, the two together and promote each other, its main purpose is to keep healthy, so also called health sports. According to a 1995 years student physical health survey results show that Chinese students although morphological development and speed, strength, quality is improved obviously, endurance, flexibility quality declining, however, students' psychological quality (willpower, competitive, resisting setback force, team spirit, etc.) is weak [5]. According to our questionnaire survey on part of the school the sports health education cannot adapt to the needs of the school education, through the teaching practice of recent years, we concluded that sports education is to enhance students' physical fitness, health for the students to promote students' physical and mental health development. Prominent health first, pay attention to the combination of sports and health education, make students understand the meaning of health, learn to care, the method of formation of sports interests.

To create happy physical education and sports education as the process of creating. To create sports is created by modern education arises at the historic moment. Create education for a long time did not cause people's attention, the modern education more on education, but it has the disadvantages of large: namely the conservatism of the strong. And human survival and development rely on is its ability to invention and creation, the history of human development is an invention of the long river, then have the ability to cultivate invention creation education. Create education in quality education today, and give it new vitality [6]. In practice, we also summarized the creation of the corresponding physical education. To create the effect of physical education is to change people's thinking method and thinking quality. In this process, teachers and students in scientific education and learning rules under the premise of positive move ideas, to create a variety of vivid environment, raises student's creation consciousness, ability, and spirit, training students' creative thinking, to cultivate students through a variety of sports activities found the problem, the ability to analyze and solve problems. Excavation of the students' creative potential, develop the students' creativity. Therefore, in the sports teaching the teacher must have creative spirit, so as to cultivate students' creation consciousness. A scale, such as basketball four football game, the 50 meters such as creating teaching successful application shows only the creative spirit, the good teaching effect can be achieved [5]. In the sports teaching, let students themselves the plait brain-storming, teacher the arrangement principles and methods of the brain-storming teach students, the students thinking through the study of theory knowledge, apply to practice make every PE lessons are full of creation, combined with a healthy the development of the sports field, full of fun. As teachers creative ability becomes more and more attention by people, and viewed as the core of teachers' quality, only creative teachers to make creative education of the students, creative talent.

For the purpose of lifelong physical education. Through teaching practice and students feedback also proves this point. Lifetime sports, in short, is a sport should not become the contents of a certain stage in life, and should be associated with people's life. In other words, people in their own life, you have choose according to their own interests, to participate in sports to enjoy sports, enhances unceasingly improve their exercise and benefit from the exercise, persistence in sports. I as far as possible, in the form of happy sports in the teaching of physical exercise, and make it a conditioned reflex sexual excitement state, for complying with the conditions of lifetime sports, become the students toward the starting point of the lifelong sports or a process [6]. Educates to reach level, many people who were sports education, may be able to speak some sports theory, but few people can really understanding it. Only skilled to master the knowledge, and be able to apply to the practice of life, this kind of education is the education to succeed. And lifelong physical education make educatereached the highest level. According to the degree of educates can be divided into three levels: one for the primary stage, namely learned some form of sports activities, technology, without fully understanding the value of sports. Secondly, the intermediate stage, namely, sports has a very good promoting effect on the body, people's physical and mental adjustment to a good condition, but the lack of subjective initiative [3]. Three for the advanced stage, aware of self to the needs of the 
movement, and form the good exercise habits, gradually improve obviously the physical and mental state. At the third stage of physical education, the educators to fully realize the sports as a necessary part of life, and self through sports to achieve unity of body and mind, persistent.

Improve the students' sports culture quality. Sports culture literacy refers to the various people combining moral elements and their quality and formed a kind of physical quality, it includes sports knowledge, sports knowledge, sports health knowledge, exercise and evaluation, competitive sports knowledge), sports skills (basic sports skills, physical exercise, entertainment, sports skill), sports consciousness, interest and habit [4]. By conducting sports interest group activities, lets the student can fully show their movement in the activities, to maintain the stability of the interest in exercise. Schools can through the rich campus sports culture activities, organize a variety of sports club in the form of teaching, make students achieve the goal of physical fitness, student teaching learning interest in the club, practice enthusiasm high, motor skills improve quickly. This and help to form lifelong exercise interest and ability and personality traits, so to the formation of students' sports culture accomplishment will have beneficial effects.

\section{Summary}

Sports as a new exercise program, for its healthy body, the leisure entertainment, the psychological adjustment, performance competition, such as multi-functional overall effect, widely attention and loved by students in the school, also brought vitality to the campus culture and window. It promote the campus spiritual civilization construction, and promote the development of the whole campus culture, and improve the students' cultural quality and aesthetic consciousness, in the campus culture plays a fitness, education, advocacy, entertainment value, on campus cultural construction and development plays a role.

\section{References}

[1] X. L. Song, Theory of adult education in common colleges and universities to cultivate practical talents, China's adult education, 2002, vol. 10, pp. 45-48.

[2] J. F. Qiu, Majesty, ordinary university sports teaching staff construction, Journal of Tianjin institute of manager, 2010, vol. 8, PP. 60-64.

[3] W. D. Shao and Q. D. Li, School physical education and sports teaching goal preunderstanding, Journal of Beijing sports university, 2010, vol. 12 pp. 96-100.

[4] X. Y. Deng, Sports teaching content system construction of rational thinking, Sports and science, 2004, vol. 5, pp. 71-75.

[5] W. M. Li, Ordinary university sports teaching model research analysis, Journal of Shandong sports institute, 2010, vol. 2, pp. 75-78.

[6] J. Zh. Zhang, Adult higher education in common colleges and universities teaching quality assurance strategy analysis, China's higher education research, 2007, vol. 4, pp. 33-37. 